\title{
Evaluation of Pt,Pd-Doped,
} NiO-Decorated, Single-Wall Carbon Nanotube-Ionic Liquid Carbon Paste Chemically Modified Electrode: An Ultrasensitive Anticancer Drug Sensor for the Determination of Daunorubicin in the Presence of Tamoxifen

OPEN ACCESS

Edited by:

Yuxin Tang,

University of Macau, China

Reviewed by:

Fatemeh Karimi,

Ton Duc Thang University, Vietnam

Mehdi Baghayeri,

Hakim Sabzevari University, Iran

${ }^{*}$ Correspondence:

Parviz Aberoomand Azar paberoomand@srbiau.ac.ir

Specialty section: This article was submitted to

Electrochemistry,

a section of the journal

Frontiers in Chemistry

Received: 17 May 2020

Accepted: 30 June 2020

Published: 19 August 2020

Citation:

Alizadeh M, Azar PA, Mozaffari SA, Karimi-Maleh $\mathrm{H}$ and Tamaddon A-M (2020) Evaluation of Pt,Pd-Doped, NiO-Decorated, Single-Wall Carbon Nanotube-Ionic Liquid Carbon Paste

Chemically Modified Electrode: An Ultrasensitive Anticancer Drug Sensor for the Determination of Daunorubicin in the Presence of Tamoxifen.

Front. Chem. 8:677.

doi: 10.3389/fchem.2020.00677

\section{Marzieh Alizadeh ${ }^{1}$, Parviz Aberoomand Azar ${ }^{1 *}$, Sayed Ahmad Mozaffari ${ }^{2}$, Hassan Karimi-Maleh ${ }^{3}$ and Ali-Mohammad Tamaddon ${ }^{4}$}

${ }^{1}$ Department of Chemistry, Science and Research Branch, Islamic Azad University, Tehran, Iran, ${ }^{2}$ Thin Layer and Nanotechnology Laboratory, Department of Chemical Technologies, Iranian Research Organization for Science and Technology (IROST), Tehran, Iran, ${ }^{3}$ Laboratory of Nanotechnology, Department of Chemical Engineering, Quchan University of Technology, Quchan, Iran, ${ }^{4}$ Center for Nanotechnology in Drug Delivery, School of Pharmacy, Shiraz University of Medical Sciences, Shiraz, Iran

Measuring the concentration of anticancer drugs in pharmacological and biological samples is a very useful solution to investigate the effectiveness of these drugs in the chemotherapy process. A Pt,Pd-doped, NiO-decorated SWCNTs (Pt,Pd-NiO/SWCNTs) nanocomposite was synthesized using a one-pot procedure and combining chemical precipitation and ultrasonic sonochemical methods and subsequently characterized by TEM and EDS analysis methods. The analyses results showed the high purity and good distribution of elements and the $\sim 10-\mathrm{nm}$ diameter of the Pt,Pd-NiO nanoparticle decorated on the surface of the SWCNTs with a diameter of about 20-30 nm. Using a combination of Pt,Pd-NiO/SWCNTs and 1-butyl-2,3-dimethylimidazolium tetrafluoroborate (1B23DTFB) in a carbon paste (CP) matrix, Pt,Pd-NiO/SWCNTs/1B23DTFB/CP was fabricated as a highly sensitive analytical tool for the electrochemical determination of daunorubicin in the concentration range of 0.008-350 $\mu \mathrm{M}$ with a detection limit of $3.0 \mathrm{nM}$. Compared to unmodified CP electrodes, the electro-oxidation process of daunorubicin has undergone significant improvements in current (about 9.8 times increasing in current) and potential (about $110 \mathrm{mV}$ ) decreasing in potential). It is noteworthy that the designed sensor can well measure daunorubicin in the presence of tamoxifen (two breast anticancer drugs with a $\Delta \mathrm{E}=315 \mathrm{mV}$. According to the real sample analysis data, the Pt,Pd-NiO/SWCNTs/1B23DTFB/CP has proved to be a promising methodology for the analysis and measuring of daunorubicin and tamoxifen in real (e.g., pharmaceutical) samples.

Keywords: daunorubicin, tamoxifen, 1-butyl-2,3-dimethylimidazolium tetrafluoroborate, Pt,Pd-doped NiO nanoparticle, cancer sensor 


\section{INTRODUCTION}

Cancer is a major disease known to be the leading cause of death in the world (Bernstein and Ross, 1993). It is estimated that more than 2.7 million cancer patients will be diagnosed worldwide by 2040 , most of them suffering from one of the four main cancers (bowel, lung, prostate, and female breast) (Bernstein and Ross, 1993). Chemotherapy and the use of anticancer drugs are known as the mainstays of treatment for most cancers (Trichopoulos et al., 1972; Bernstein and Ross, 1993; Radwan et al., 2019). Therefore, much research is being done on the identification, efficacy, side effects, and effects of anticancer drug concentrations on the derma process and on the combined effect of anticancer drugs in the chemotherapy process (Delaney et al., 2005; Moseley et al., 2007; Andersen and Kehlet, 2011). Accordingly, research work in this area is of great importance for the global health sector (Moseley et al., 2007).

Daunorubicin in injectable form was introduced as a chemotherapy drug for different types of cancers, such as chronic and acute myelogenous leukemia and breast cancer (Skovsgaard, 1978; Slater et al., 1982; Raut, 2015). Daunorubicin, commonly prescribed in combination with other anticancer drugs in chemotherapy, such as tamoxifen, is used to reduce the side effects of surgery and the reinfection risk of breast cancer (Reiffers et al., 1996; Guo and Lu, 2010; Shien et al., 2014). Numerous studies have investigated the effects and benefits of the simultaneous use of daunorubicin and tamoxifen on the human body (Shao et al., 2012; Li et al., 2014). Therefore, this research has focused on the analysis of daunorubicin in the presence of tamoxifen.

There are different analytical strategies for the determination of daunorubicin separately or in the presence of other anticancer drugs (Hulhoven and Desager, 1977; Wang et al., 1987; Hu et al., 2000; Gavenda et al., 2001; Jiang et al., 2003). Electrochemical methods are attractive; fast, inexpensive, non-polluting analyses with good kit ability make such techniques more appealing than other analytical methods (Yuan et al., 2013, 2017, 2019, 2020; Fu et al., 2018, 2019a,b,c, 2020; Xu et al., 2018). However, the ability of electrochemical sensors to detect inappropriate levels is still limited due to the weak signal of pharmaceutical and biological compounds on the surface of unmodified sensors (Karimi-Maleh et al., 2017, 2020a,b; Ghanei-Motlagh and Baghayeri, 2020; Nodehi et al., 2020). With the replacement of simple sensors with electrochemical modified sensors in recent years, it has been possible to sensitively and selectively measure important drug compounds, especially anticancer drugs (Karimi-Maleh et al., 2019a; Khodadadi et al., 2019; Baghayeri et al., 2020; KarimiMaleh and Arotiba, 2020; Mohanraj et al., 2020). Nanomaterials with new and wonderful features are important options in various fields in recent years (Rayati and Malekmohammadi, 2016; Asl, 2017; Malekmohammadi et al., 2018a,b; Orooji et al., 2019a,b,c; Karimi-Maleh et al., 2020c; Nguyen et al., 2020). Different types of nanomaterials have been synthesized and used as powerful materials in the recent years (Keyvanfard et al., 2014; Nayebi et al., 2016; Parvizi et al., 2018; Asl et al., 2020; Fattahi et al., 2020; Sakkaki et al., 2020). Metal-based nanomaterials, such as $\mathrm{NiO}, \mathrm{SiO}, \mathrm{Au}, \mathrm{TiO}_{2}, \mathrm{ZnO}, \mathrm{Pt}$, and $\mathrm{Pd}$ showed high catalytic activity in different fields and especially electrochemical systems (Yang et al., 2010; Baghayeri et al., 2013, 2019; Mozaffari et al., 2014, 2015; Rahmanian and Mozaffari, 2015; Rahmanian et al., 2015; Asrami et al., 2017, 2018; Karimi-Maleh et al., 2019b, 2020d; Tahernejad-Javazmi et al., 2019). Recently, metal-doped metal oxide nanoparticles, such as the Pt-doped $\mathrm{NiO}$ nanoparticle were used as a high-performance electrocatalyst in fabrication of electrochemical sensors (Dehdashti and Babaei, 2020).

Ionic liquids are new conductive materials with excellent electrical conductivity that have garnered much attention and have been widely used as modifiers in the last 20 years (Atta et al., 2019; Shamsadin-Azad et al., 2019). Many researchers have demonstrated the separate or combined use of ionic liquids with nanomaterials to design electrochemical sensors (Alavi-Tabari et al., 2018; Beytur et al., 2018; Li et al., 2019).

According to studies and reviews of articles published in the field of electrochemical sensors, no research has been done on measuring daunorubicin in the presence of tamoxifen, and therefore, this project has undertaken the construction of an electrochemical sensor for this purpose. To that end, Pt,Pd$\mathrm{NiO} / \mathrm{SWCNTs} / 1 \mathrm{~B} 23 \mathrm{DTFB} / \mathrm{CP}$ was fabricated. The synergic effect of the $\mathrm{Pt}, \mathrm{Pd}-\mathrm{NiO} / \mathrm{SWCNTs}$ nanocomposite and 1B23DTFB helped improve the ability of sensors to make highly sensitive determinations of daunorubicin under optimum conditions. In addition, this synergic effect created an interesting condition for determining daunorubicin in the presence of tamoxifen in real samples.

\section{MATERIALS AND METHODS}

\section{Instrumentation}

The electrochemical part of this research was performed using an electrochemical workstation model Ivium-Vertex connected to an electrochemical cell (Azar Electrode Company, Iran). The TEM (made in Germany, model Zeiss-EM10C-100 kV) was used to characterize the $\mathrm{Pt}, \mathrm{Pd}-\mathrm{NiO} / \mathrm{SWCNTs}$ nanocomposite. All recorded voltammograms are based on the $\mathrm{Ag} / \mathrm{AgCl} / \mathrm{KCl}_{\text {sat }}$ reference electrode (Azar Electrode Company) potential.

\section{Reagents}

Daunorubicin, hydrochloride, sodium hydroxide, tamoxifen, 1butyl-2,3-dimethylimidazolium tetrafluoroborate, and SWCNTs were bought from Sigma-Aldrich. Carbon powder, nickel nitrate hexahydrate, paraffin oil, phosphoric acid, and platinum(II) acetylacetonate were bought from Merck Company. 0.001 M stock solutions of daunorubicin, hydrochloride, and tamoxifen were prepared in $100 \mathrm{~mL}$ distillated water by dissolving 0.56 and $0.37 \mathrm{~g}$ anticancer drugs under stirring $(150 \mathrm{rpm})$ and ultrasonication conditions, respectively.

\section{Synthesis of the Pt,Pd-NiO/SWCNTs Nanocomposite}

$1.0 \mathrm{~g}$ SWCNTs-COOH was dispersed in $100 \mathrm{~mL}$ distillated water solution under stirring conditions. Next, $0.182 \mathrm{~g}$ nickel nitrate hexahydrate $+0.016 \mathrm{~g}$ palladium dichloride and $0.016 \mathrm{~g}$ platinum(II) acetylacetonate were added to this solution, and stirring was continued for $30 \mathrm{~min}$ at $45^{\circ} \mathrm{C}$. Afterward, $100 \mathrm{~mL}$ 

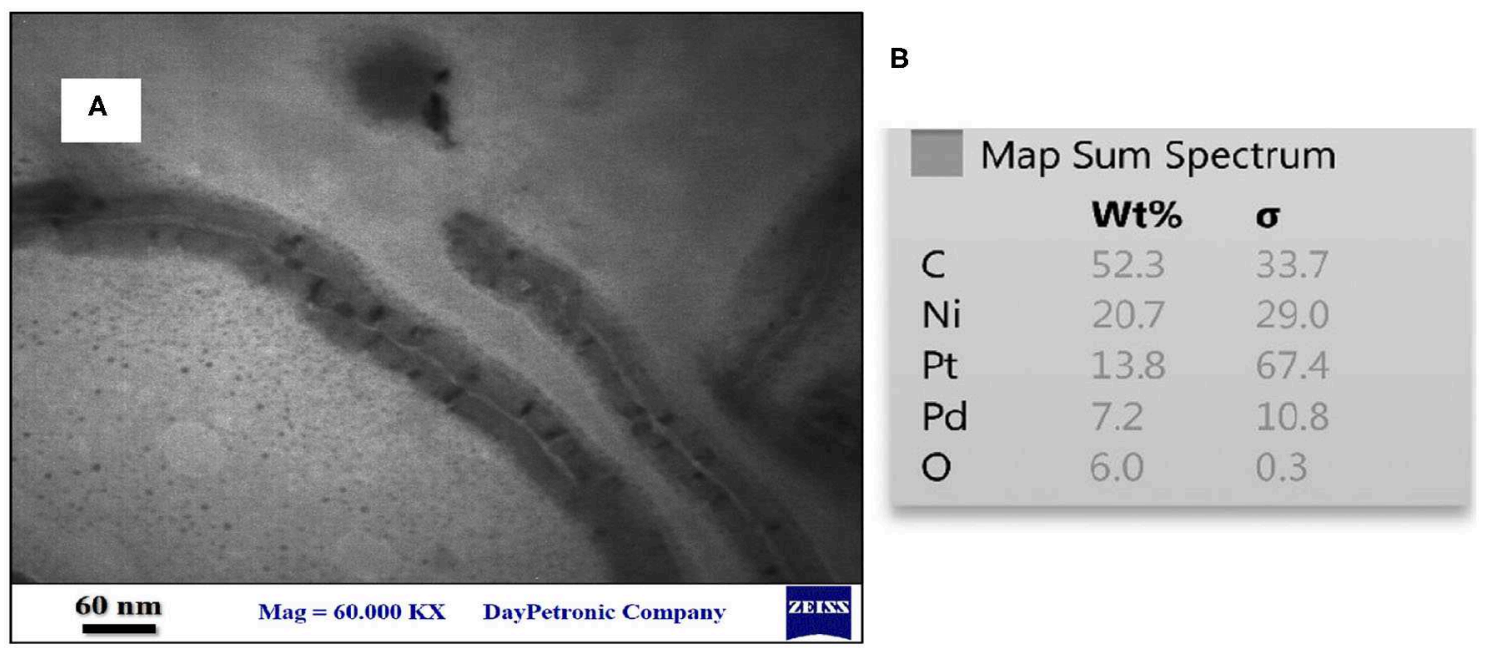

FIGURE 1 | (A) TEM and (B) EDS images of Pt,Pd-NiO/SWCNT nanocomposites.

sodium hydroxide $0.2 \mathrm{M}$ was added to the solution with no change in temperature or stirring speed. The obtained sample was dried in a vacuum oven at $100^{\circ} \mathrm{C}$ for $4 \mathrm{~h}$. The black powder was then transferred into a furnace and calcinated for $4.0 \mathrm{~h}$ at $400^{\circ} \mathrm{C}$.

\section{Preparation of Pt,Pd-NiO/SWCNTs/1B23DTFB/CP}

The ratio of $\mathrm{Pt}, \mathrm{Pd}-\mathrm{NiO} / \mathrm{SWCNT}$ and $1 \mathrm{~B} 23 \mathrm{DTFB}$ in preparation of $\mathrm{Pt}, \mathrm{Pd}-\mathrm{NiO} / \mathrm{SWCNTs} / 1 \mathrm{~B} 23 \mathrm{DTFB} / \mathrm{CP}$ were optimized in the presence of $500 \mu \mathrm{M}$ daunorubicin (Figures S1, S2). Pt,Pd$\mathrm{NiO} / \mathrm{SWCNTs} / 1 \mathrm{~B} 23 \mathrm{DTFB} / \mathrm{CP}$ was developed by mixing carbon powder and $\mathrm{Pt}, \mathrm{Pd}-\mathrm{NiO} / \mathrm{SWCNTs}$ as powder components in the ratio of 94:6 (w/w) and paraffin oil and 1B23DTFB as liquid binders in the ratio of $8: 2(\mathrm{v} / \mathrm{v})$. The mixture was then carefully homogenized in an agate mortar using a pestle. The obtained paste was packed into a glass tube, and a copper wire was used for electrical contact.

\section{Real Sample Preparation}

The injection and pharmaceutical serum samples were prepared from a local pharmacy and used as real samples for investigating the ability of Pt,Pd-NiO/SWCNTs/1B23DTFB/CP as a new analytical tool to determine daunorubicin and tamoxifen (Nolvadex). The samples were used directly and without any pretreatment. The standard addition method was selected as the analytical strategy for this goal.

\section{RESULTS AND DISCUSSION}

\section{Characterization of the Pt,Pd-NiO/SWCNTs Nanocomposite}

The synthesized Pt,Pd-NiO/SWCNTs was characterized by different powerful methods, such as TEM and EDS. The recorded results relative to morphological investigation (TEM) is presented in Figure 1A. The decorated nanoparticle on the surface of the SWCNTs is clearly shown in the TEM image. The particle size of about $10 \mathrm{~nm}$ was estimated for the $\mathrm{Pt}, \mathrm{Pd}-\mathrm{NiO}$ nanoparticle decorated on the surface of the SWCNTs. Figure 1B (EDS analysis data) successfully confirms the presence of $\mathrm{Pt}, \mathrm{Pd}$, $\mathrm{Ni}$, and $\mathrm{O}, \mathrm{C}$ elements in the Pt,Pd-NiO/SWCNTs structure, which approves high purity in the synthesis procedure.

\section{Electrochemical Behavior of Daunorubicin}

The I-V response of daunorubicin was recorded in different $\mathrm{pH}$ ( $\mathrm{pH}$ range 5.0-9.0) values in order to study the effect of proton concentration in the current and potential of the anticancer drug (Figure 2 inset). The plot of $\mathrm{E}$ vs. $\mathrm{pH}$ showed a linear relation with equation $\mathrm{E}_{\mathrm{pa}}=0.061 \mathrm{pH}+1.049\left(R^{2}=0.998\right)$ on the surface of $\mathrm{Pt}, \mathrm{Pd}-\mathrm{NiO} / \mathrm{SWCNTs} / 1 \mathrm{~B} 23 \mathrm{DTFB} / \mathrm{CP}$ as an electrochemical sensor. This value of slope (0.061) confirmed equal electron and proton values in the redox reaction of daunorubicin on the surface of $\mathrm{Pt}, \mathrm{Pd}-\mathrm{NiO} / \mathrm{SWCNTs} / 1 \mathrm{~B} 23 \mathrm{DTFB} / \mathrm{CP}$ (Figure 2). In comparing oxidation signals (I-V curves), the best oxidation signal was observed at $\mathrm{pH}=7.0$ (Figure S3). Therefore, $\mathrm{pH}=$ 7.0 can be selected as the best electrochemical condition for the analysis of daunorubicin.

\section{Role of Pt,Pd-NiO/SWCNTs and 1B23DTFB in the Prepared Sensor}

The role of $\mathrm{Pt}, \mathrm{Pd}-\mathrm{NiO} / \mathrm{SWCNTs}$ and $1 \mathrm{~B} 23 \mathrm{DTFB}$ in the fabrication of Pt,Pd-NiO/SWCNTs/1B23DTFB/CP and their effects on the oxidation signal of daunorubicin were investigated by the $\mathrm{I}-\mathrm{V}$ method. As can be seen, daunorubicin showed a weak oxidation signal with a current of $7.74 \mu \mathrm{A}$ and potential of $720 \mathrm{mV}$ on the surface of the carbon paste electrode (Figure 3, Curve a). After modification of the $\mathrm{CPE}$ with the $\mathrm{Pt}, \mathrm{Pd}-\mathrm{NiO} / \mathrm{SWCNTs}$ nanocomposite, the oxidation current of daunorubicin improved to $40.25 \mu \mathrm{A}$, and the oxidation potential of daunorubicin was decreased to $680 \mathrm{mV}$ (Figure 3, Curve b). Under the same conditions and after modification of the CPE with 1 B23DTFB as a binder, the oxidation current of daunorubicin was improved 


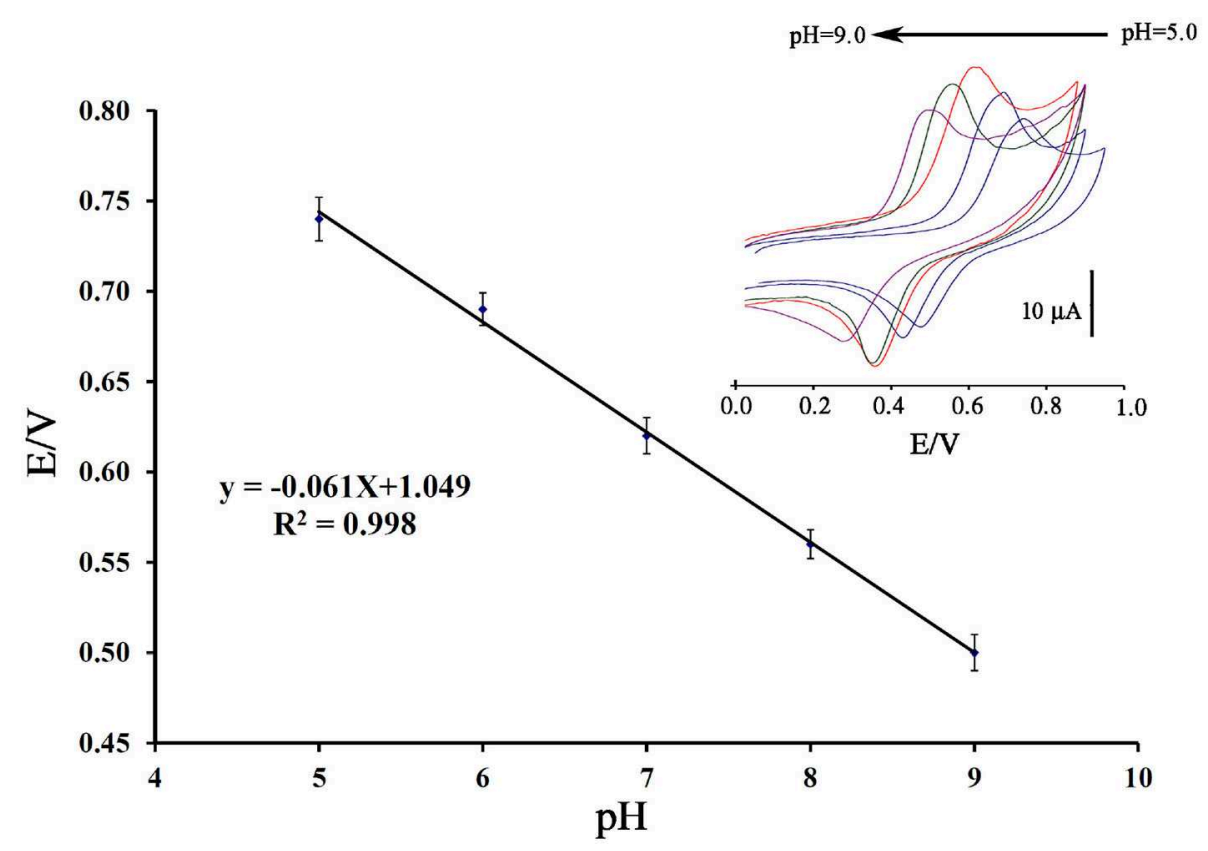

FIGURE 2 | E-pH plot relative to electro-oxidation of $200 \mu \mathrm{M}$ daunorubicin at the surface of Pt,Pd-NiO/SWCNTs/1B23DTFB/CP ( $n=4)$. (Inset) I-V curves of 200 $\mu$ M daunorubicin at the surface of Pt,Pd-NiO/SWCNTs/1B23DTFB/CP in the pH range 5.0-9.0.

to $50.35 \mu \mathrm{A}$, and the oxidation potential of daunorubicin was decreased to $670 \mathrm{mV}$ (Figure 3, Curve c). These improvements in the redox reaction of daunorubicin by $\mathrm{Pt}, \mathrm{Pd}-\mathrm{NiO} / \mathrm{SWCNTs}$ and $1 \mathrm{~B} 23 \mathrm{DTFB}$ are correlated with the good electrical conductivity of the mediators. Therefore, the modification of $\mathrm{CPE}$ with $\mathrm{Pt}, \mathrm{Pd}-\mathrm{NiO} / \mathrm{SWCNTs}$ and 1B23DTFB and making Pt,Pd-NiO/SWCNTs/1B23DTFB/CP a highly conductive sensor were selected. On the surface of the $\mathrm{Pt}, \mathrm{Pd}-\mathrm{NiO} / \mathrm{SWCNTs} / 1 \mathrm{~B} 23 \mathrm{DTFB} / \mathrm{CP}$, the oxidation current of daunorubicin was about $76.04 \mu \mathrm{A}$, and the oxidation potential of daunorubicin was decreased to $610 \mathrm{mV}$ (Figure 3, curve d). Comparing the oxidation signal of daunorubicin on the surface of $\mathrm{CPE}$ with $\mathrm{Pt}, \mathrm{Pd}-\mathrm{NiO} / \mathrm{SWCNTs} / 1 \mathrm{~B} 23 \mathrm{DTFB} / \mathrm{CP}$ revealed a 9.8-times increase in current and a decrease of about $110 \mathrm{mV}$ in the oxidation potential of the drug. The effects of Pt,Pd$\mathrm{NiO} / \mathrm{SWCNTs}$ and 1B23DTFB on improving conductivity of the sensor were investigated by recording current density data. For this goal and in the first step, the active surface areas of the CPE, Pt,Pd-NiO/SWCNTs/CP, 1B23DTFB/CP, and Pt,Pd$\mathrm{NiO} / \mathrm{SWCNTs} / 1 \mathrm{~B} 23 \mathrm{DTFB} / \mathrm{CP}$ were calculated to be about 0.13 , $0.19,0.2$, and $0.22 \mathrm{~cm}^{2}$, respectively. Using active surface area data and the oxidation current of daunorubicin on the surface of different electrodes, the current density data was drawn and is shown in the inset of Figure 3. The diagrams confirm the improved conductivity of $\mathrm{CPE}$ after modification with $\mathrm{Pt}, \mathrm{Pd}-\mathrm{NiO} / \mathrm{SWCNT}$ nanocomposite and 1B23DTFB.

The I-V signals of $100 \mu \mathrm{M}$ daunorubicin on the surface of $\mathrm{Pt}, \mathrm{Pd}-\mathrm{NiO} / \mathrm{SWCNTs} / 1 \mathrm{~B} 23 \mathrm{DTFB} / \mathrm{CP}$ and in the scan rate range of $10-450 \mathrm{mV} / \mathrm{s}$ were recorded under optimum conditions (Figure 4 inset). The results of the relationship between the current of daunorubicin and $\nu^{1 / 2}$ on the surface of $\mathrm{Pt}$,Pd-NiO/SWCNTs/1B23DTFB/CP are shown in Figure 4. The equation $\mathrm{I}_{\mathrm{pa}}=1.9238 \nu^{1 / 2}-4.1438\left(R^{2}=0.9942\right)$ was recorded for this study. This equation and the linear relation between current and $v^{1 / 2}$ on the surface of Pt,Pd$\mathrm{NiO} / \mathrm{SWCNTs} / 1 \mathrm{~B} 23 \mathrm{DTFB} / \mathrm{CP}$ suggest that the electro-oxidation of daunorubicin is under the diffusion control.

Figure 5 shows the Tafel plot relative to oxidation of $100 \mu \mathrm{M}$ daunorubicin at the surface of Pt,Pd$\mathrm{NiO} / \mathrm{SWCNTs} / 1 \mathrm{~B} 23 \mathrm{DTFB} / \mathrm{CP}$. Using the slope of the Tafel plot, the value of $\alpha$ was calculated 0.8 .

With the confirmation of the diffusion process during the daunorubicin oxidation process on the surface of $\mathrm{Pt}, \mathrm{Pd}$ $\mathrm{NiO} / \mathrm{SWCNTs} / 1 \mathrm{~B} 23 \mathrm{DTFB} / \mathrm{CP}$, the chronoamperometric method with applied potential of $750 \mathrm{mV}$ was used to determine the diffusion coefficient (D) of daunorubicin (Figure 6). The inset in Figure 6 shows the Cottrell plots relative to daunorubicin oxidation on the surface of Pt,Pd-NiO/SWCNTs/1B23DTFB/CP. Using the obtained slopes relative to daunorubicin oxidation in the different concentration ranges and on the surface of $\mathrm{Pt}, \mathrm{Pd}$ $\mathrm{NiO} / \mathrm{SWCNTs} / 1 \mathrm{~B} 23 \mathrm{DTFB} / \mathrm{CP}$, the value of $\mathrm{D}$ was calculated to be about $1.43 \times 10^{-5} \mathrm{~cm}^{2} / \mathrm{s}$.

\section{Stability Investigation of Pt,Pd-NiO/SWCNTs/1B23DTFB/CP}

The storage stability of $\mathrm{Pt}, \mathrm{Pd}-\mathrm{NiO} / \mathrm{SWCNTs} / \mathrm{B} 23 \mathrm{DTFB} / \mathrm{CP}$ was investigated by storing the amplified daunorubicin sensor for 40 days. The Pt,Pd-NiO/SWCNTs/1B23DTFB/CP had maintained $90.0 \%$ of its initial current in the presence of $500 \mu \mathrm{M}$ daunorubicin after 1 month; after this time, the 


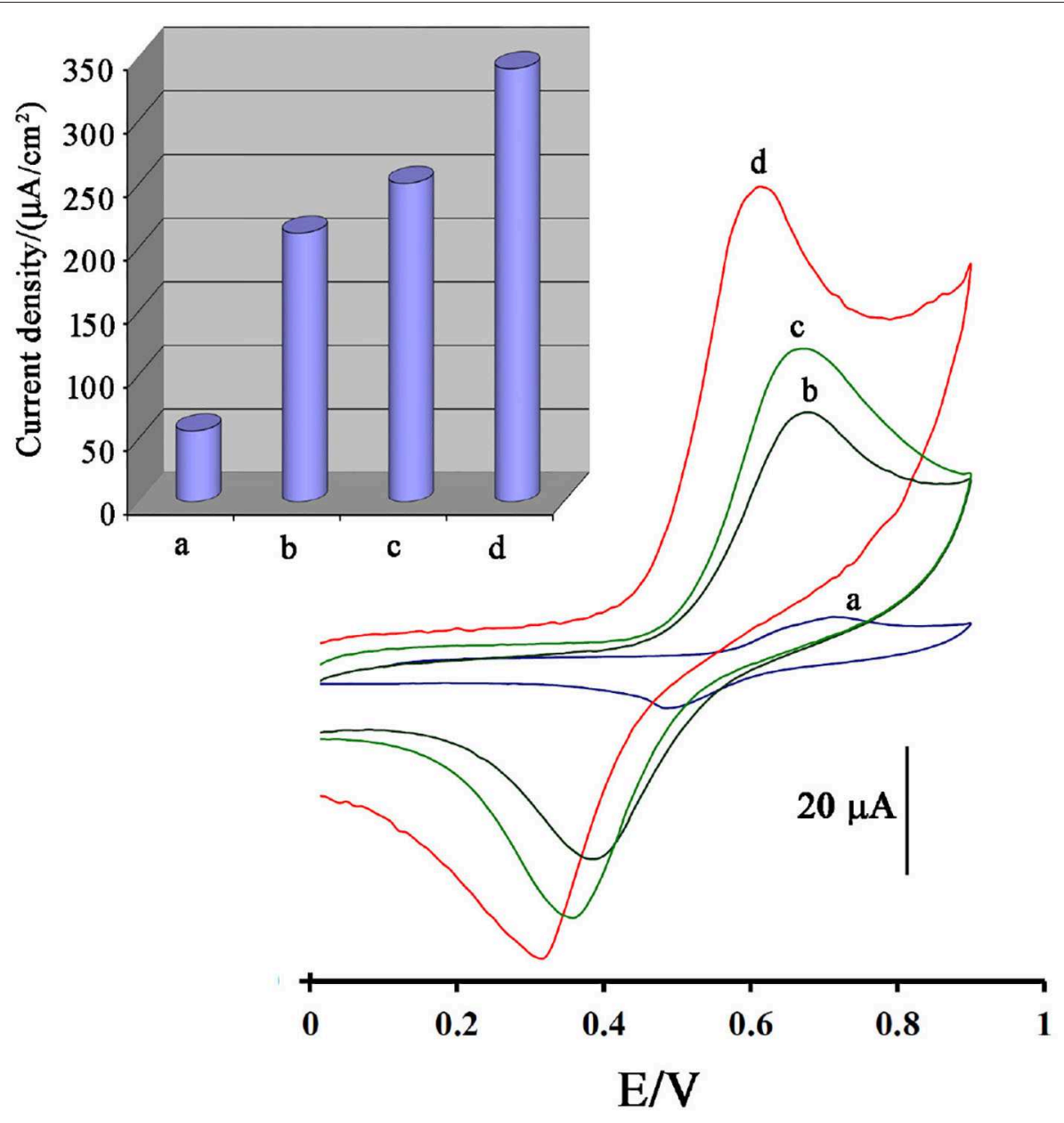

FIGURE 3 | Cyclic voltammograms $500 \mu \mathrm{M}$ daunorubicin at surface of (a) CPE; (b) Pt,Pd-NiO/SWCNTs/CP; (c) B23DTFB/CP; and (d) Pt,Pd-NiO/SWCNTs/1B23DTF $\mathrm{B} / \mathrm{CP}$. (Inset) Current density data relative electro-oxidation of $500 \mu \mathrm{M}$ daunorubicin at surface of different electrodes.

current was drastically reduced, which confirmed that $\mathrm{Pt}, \mathrm{Pd}$ $\mathrm{NiO} / \mathrm{SWCNTS} / 1 \mathrm{~B} 23 \mathrm{DTFB} / \mathrm{CP}$ had the ability to efficiently and analytically measure daunorubicin (Figure S4).

\section{Analytical Approach for the Simultaneous Determination of Daunorubicin in the Presence of Tamoxifen}

According to previous reports, daunorubicin and tamoxifen may be present simultaneously in biological solutions. Accordingly, the $\mathrm{Pt}, \mathrm{Pd}-\mathrm{NiO} / \mathrm{SWCNTs} / 1 \mathrm{~B} 23 \mathrm{DTFB} / \mathrm{CP}$ 's ability to determine these two anticancer drugs was examined. The differential pulse voltammograms (DPVs) of daunorubicin were recorded on the surface of $\mathrm{Pt}, \mathrm{Pd}-\mathrm{NiO} / \mathrm{SWCNTs} / 1 \mathrm{~B} 23 \mathrm{DTFB} / \mathrm{CP}$, and a linear relation between current and daunorubicin concentration was observed in the range of $0.008-350 \mu \mathrm{M}$ with equation $\mathrm{I}_{\mathrm{pa}}=0.2351 \mathrm{C}_{\text {daunorubicin }}+2.7029\left(R^{2}=\right.$ 0.9954) (Figure S5). The differential pulse voltammograms of tamoxifen were also recorded on the surface of $\mathrm{Pt}, \mathrm{Pd}$ $\mathrm{NiO} / \mathrm{SWCNTS} / 1 \mathrm{~B} 23 \mathrm{DTFB} / \mathrm{CP}$, and a linear relation between current and tamoxifen concentration was observed in the range of 0.5-330 $\mu \mathrm{M}$ with equation $\mathrm{I}_{\mathrm{pa}}=0.4178 \mathrm{C}_{\text {tamoxifen }}+0.0867$ $\left(R^{2}=0.9983\right)$ (Figure S6). Pt,Pd-NiO/SWCNTs/1B23DTFB/CP showed detection limits of $3.0 \mathrm{nM}$ and $0.1 \mu \mathrm{M}$ for daunorubicin and tamoxifen, respectively.

The DP voltammograms of the solutions containing different concentrations of daunorubicin + tamoxifen were recorded on the surface of Pt,Pd-NiO/SWCNTs/1B23DTFB/CP (Figure 7A). The plots of current vs. concentration of daunorubicin or tamoxifen (for this study) are presented in Figures 7B,C. The results for the slopes presented in Figures 7A,B are quite similar to the results for separate drug analyses. As an example, the investigation of the linear dynamic range for daunorubicin alone showed a slope of $0.2351 \mu \mathrm{A} / \mu \mathrm{M}$. This value of sensitivity is very close to the recorded sensitivity in simultaneous analyses $(0.2267 \mu \mathrm{A} / \mu \mathrm{M})$. Two separated oxidation signals were observed in the solutions containing different concentrations of daunorubicin + tamoxifen with $\Delta \mathrm{E}=315 \mathrm{mV}$. These results confirm the powerful and selective ability of $\mathrm{Pt}, \mathrm{Pd}$ $\mathrm{NiO} / \mathrm{SWCNTs} / 1 \mathrm{~B} 23 \mathrm{DTFB} / \mathrm{CP}$ as an electroanalytical sensor for the determination of daunorubicin in the presence of tamoxifen. 


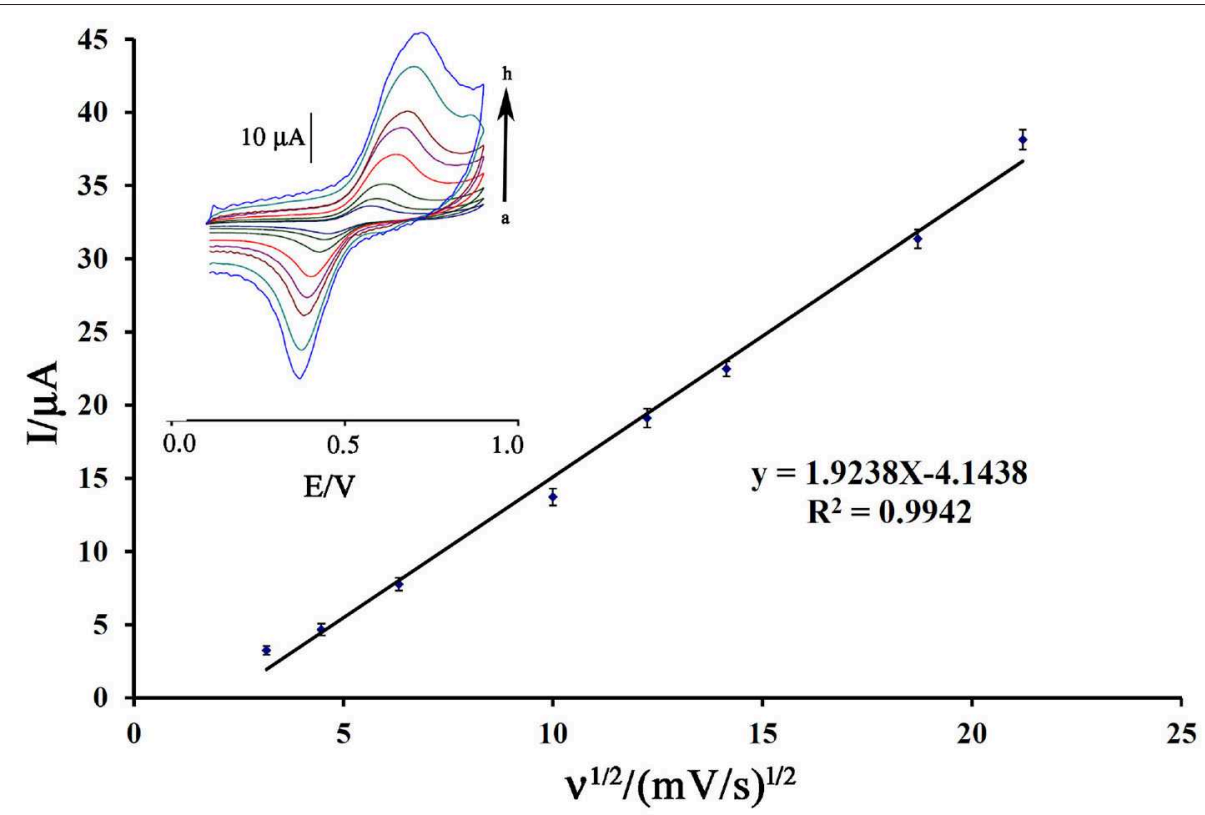

FIGURE 4 | I- $\nu^{1 / 2}$ plot relative to electro-oxidation of $100 \mu \mathrm{M}$ daunorubicin at surface of Pt,Pd-NiO/SWCNTs/1B23DTFB/CP ( $\left.n=4\right)$. (Inset) Cyclic voltammograms of $100 \mu \mathrm{M}$ daunorubicin at the surface of Pt,Pd-NiO/SWCNTs/1B23DTFB/CP at scan rates (a) 10.0; (b) 20.0; (c) 40.0; (d) 100.0; (e) 150.0; (f) 200.0; (g) 350.0; and (h) $450.0 \mathrm{mV} / \mathrm{s}$.

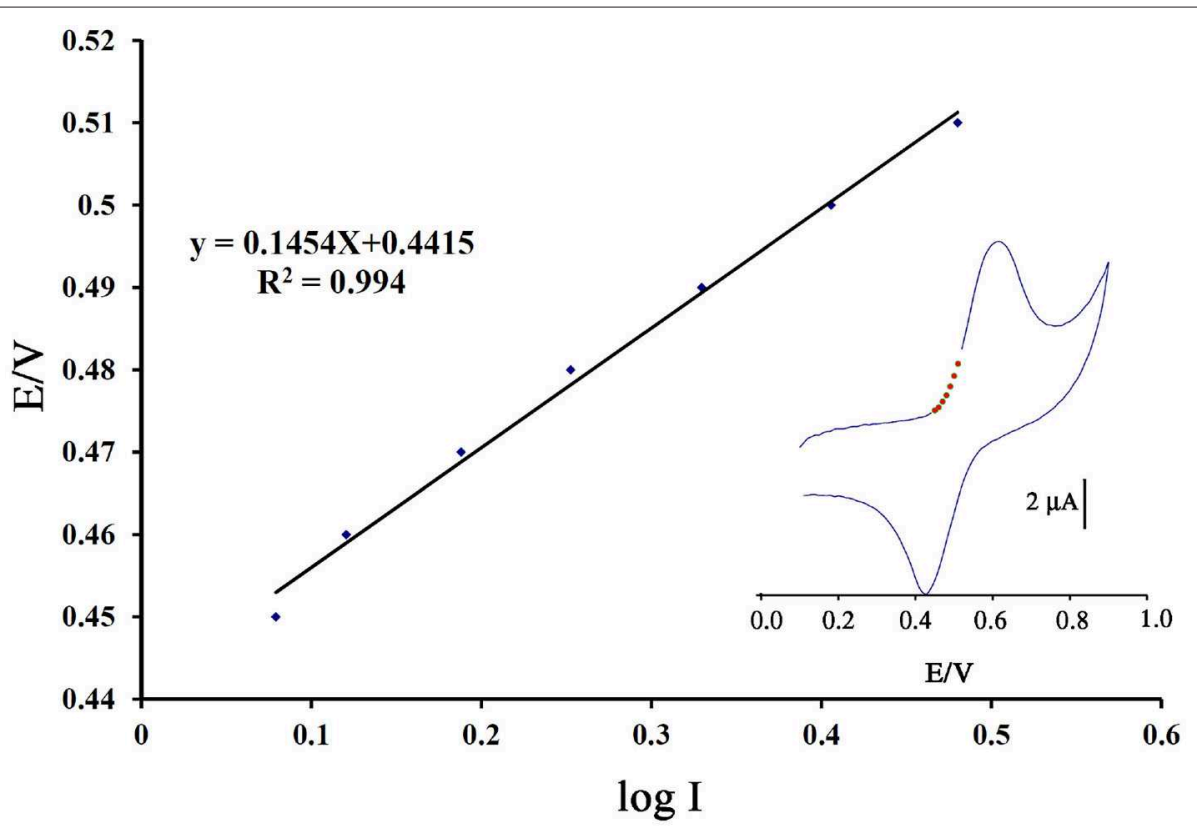

FIGURE 5 | Tafel plot for Pt,Pd-NiO/SWCNTs/1B23DTFB/CP with a scan rate of $10 \mathrm{mV} / \mathrm{s}$ in the presence of $100 \mu \mathrm{M}$ daunorubicin.

\section{Real Sample and Interference Studies}

The selectivity of Pt,Pd-NiO/SWCNTs/1B23DTFB/CP for the determination of daunorubicin was investigated in this step. The results are presented in Table $\mathbf{S 1}$ and confirm the selectivity of $\mathrm{Pt}, \mathrm{Pd}-\mathrm{NiO} / \mathrm{SWCNTs} / 1 \mathrm{~B} 23 \mathrm{DTFB} / \mathrm{CP}$ as a new electroanalytical sensor for the determination of daunorubicin.
In the final step, the ability of Pt,Pd$\mathrm{NiO} / \mathrm{SWCNTs} / 1 \mathrm{~B} 23 \mathrm{DTFB} / \mathrm{CP}$ to determine daunorubicin in different real samples, such as injection and pharmaceutical serums, was checked using the standard addition method. A recovery rate of $96.86-102.25 \%$ was detected, confirming the high capability of Pt,Pd-NiO/SWCNTs/1B23DTFB/CP 


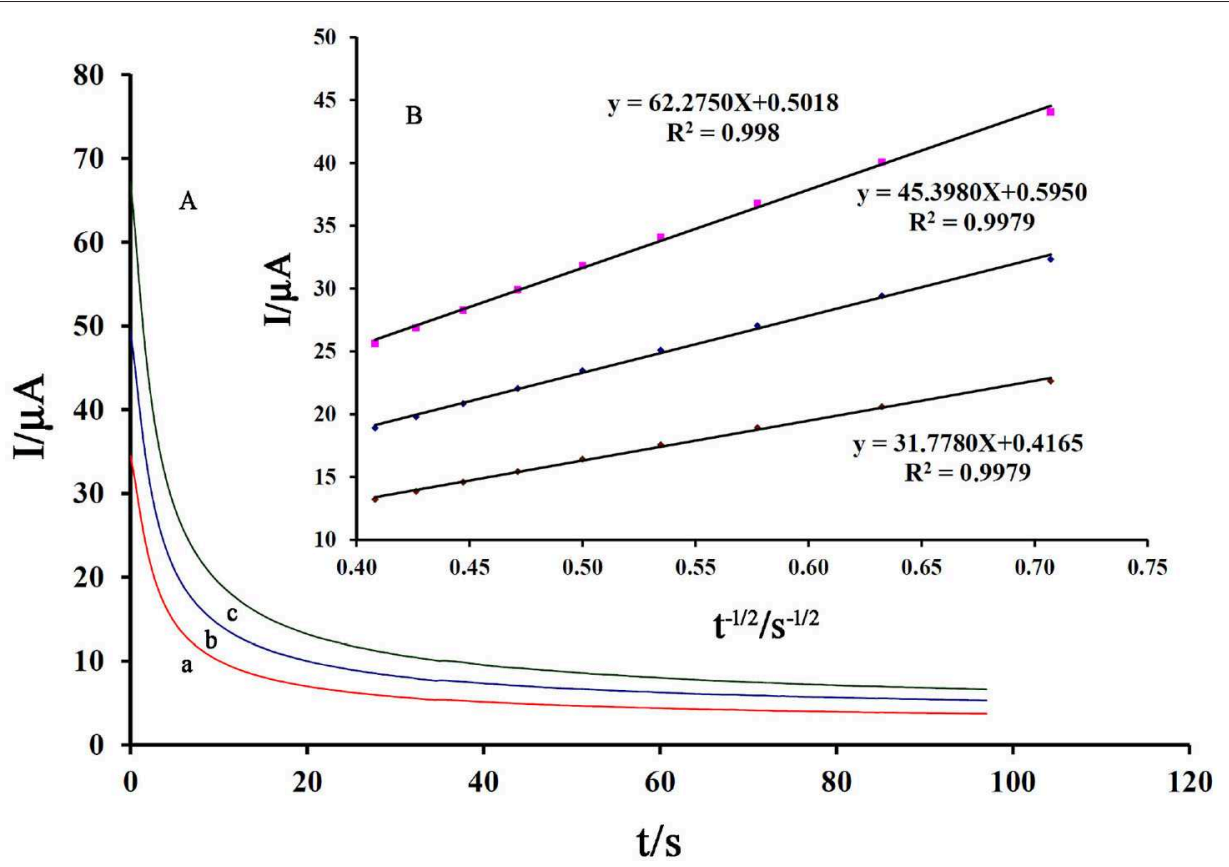

FIGURE 6 | (A) Chronoamperograms obtained at Pt,Pd-NiO/SWCNTs/1B23DTFB/CP in the solution containing (a) 400, (b) 500, and (c) $600 \mu \mathrm{M}$ daunorubicin. (B) Cottrell plots obtained from chronoamperogram signals.

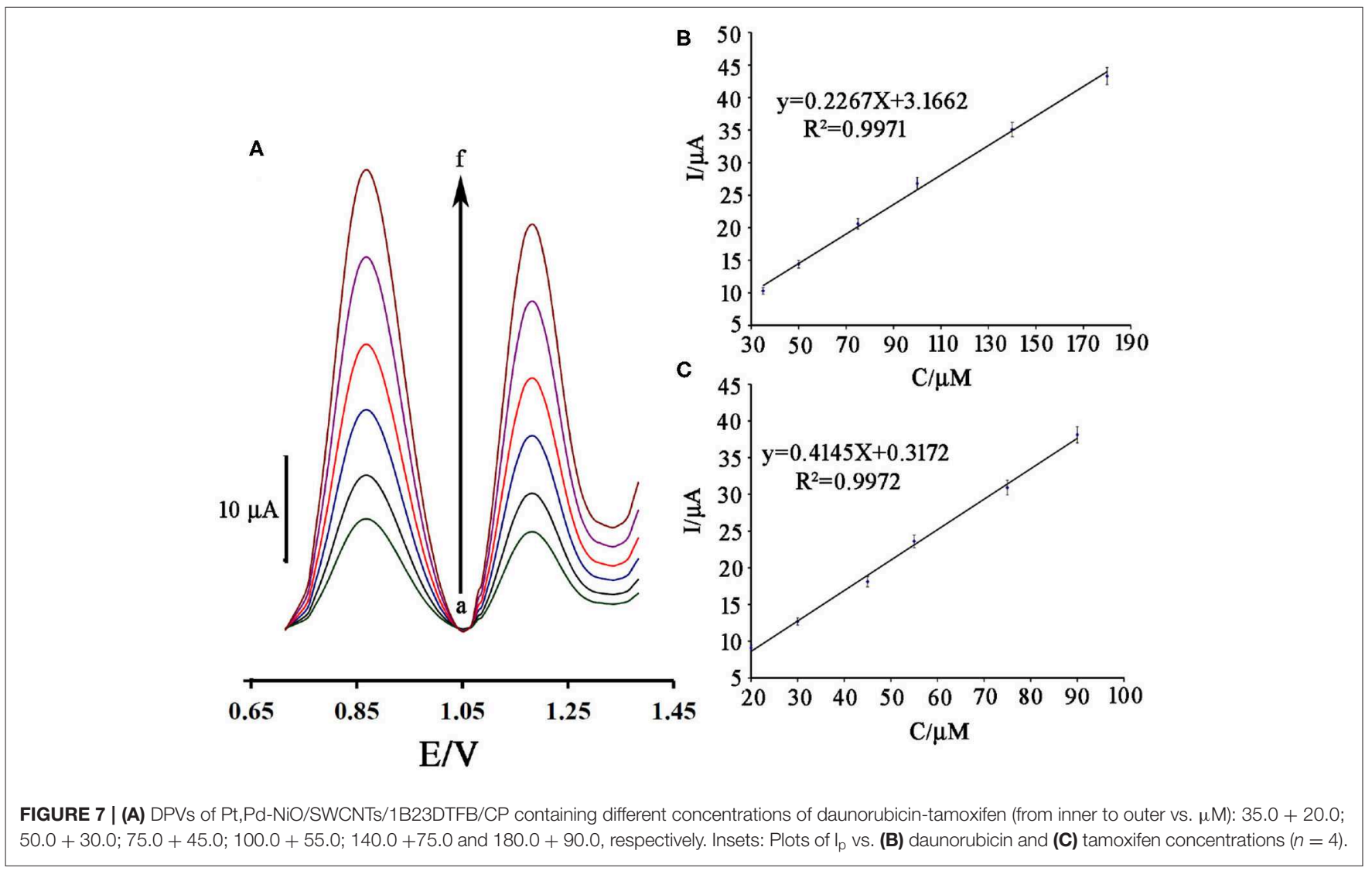


TABLE 1 | Determination of daunorubicin and tamoxifen in real samples $(n=4)$.

\begin{tabular}{|c|c|c|c|c|c|c|}
\hline Samples & $\begin{array}{l}\text { Daunorubicin } \\
\text { added }(\mu M)\end{array}$ & $\begin{array}{c}\text { Tamoxifen } \\
\text { added }(\mu \mathrm{M})\end{array}$ & $\begin{array}{c}\text { Founded of } \\
\text { daunorubicin } \\
(\mu \mathrm{M})\end{array}$ & $\begin{array}{l}\text { Founded of } \\
\text { tamoxifen } \\
(\mu \mathrm{M})\end{array}$ & $\begin{array}{c}\text { Recovery \% } \\
\text { of } \\
\text { daunorubicin }\end{array}$ & $\begin{array}{l}\text { Recovery\% } \\
\text { of tamoxifen }\end{array}$ \\
\hline \multirow[t]{2}{*}{ Injection samples of daunorubicin } & - & - & $2.04 \pm 0.11$ & - & - & - \\
\hline & 5.00 & - & $7.08 \pm 0.21$ & - & 100.5 & - \\
\hline \multirow[t]{2}{*}{ Dextrose saline } & - & - & $<L O D$ & $<$ LOD & - & - \\
\hline & 35.00 & 20.00 & $34.79 \pm 0.66$ & $20.54 \pm 0.63$ & 99.4 & 102.25 \\
\hline \multirow[t]{2}{*}{ Injection samples of tamoxifen } & - & - & - & $5.11 \pm 0.34$ & - & - \\
\hline & - & 5.00 & - & $4.95 \pm 0.76$ & - & 96.86 \\
\hline
\end{tabular}

in determining daunorubicin and tamoxifen in real samples (Table 1).

\section{CONCLUSION}

In this study, $\mathrm{Pt}, \mathrm{Pd}-\mathrm{NiO} / \mathrm{SWCNTs}$ were synthesized using the one-pot procedure and combining chemical precipitation and ultrasonic sonochemical deposition methods. The characterization data confirmed the good purity and distribution for the synthesized nanocomposite, which also showed the improved conductivity effect of the fabricated sensor for the determination of daunorubicin. It is noteworthy that the designed sensor can well measure daunorubicin in the presence of tamoxifen (two breast anticancer drugs with a $\Delta \mathrm{E}=315 \mathrm{mV}$. Pt,Pd-NiO/SWCNTs/1B23DTFB/CP showed a good ability for determining daunorubicin and tamoxifen with detection limits of $3.0 \mathrm{nM}$ and $0.1 \mu \mathrm{M}$, respectively. Pt,Pd$\mathrm{NiO} / \mathrm{SWCNTs} / 1 \mathrm{~B} 23 \mathrm{DTFB} / \mathrm{CP}$ also showed a recovery range of 96.86-102.25\% for the analyses of daunorubicin and tamoxifen,

\section{REFERENCES}

Alavi-Tabari, S. A., Khalilzadeh, M. A., and Karimi-Maleh, H. (2018). Simultaneous determination of doxorubicin and dasatinib as two breast anticancer drugs uses an amplified sensor with ionic liquid and $\mathrm{ZnO}$ nanoparticle. J. Electroanal. Chem. 811, 84-88. doi: 10.1016/j.jelechem.2018. 01.034

Andersen, K. G., and Kehlet, H. (2011). Persistent pain after breast cancer treatment: a critical review of risk factors and strategies for prevention. J. Pain 12, 725-746. doi: 10.1016/j.jpain.2010.12.005

Asl, M. S. (2017). Microstructure, hardness and fracture toughness of spark plasma sintered $\mathrm{ZrB}_{2}$-SiC-Cf composites. Ceramics Int. 43, 15047-15052. doi: 10.1016/j.ceramint.2017.08.030

Asl, M. S., Pazhouhanfar, Y., Namini, A. S., Shaddel, S., Fattahi, M., and Mohammadi, M. (2020). Role of graphite nano-flakes on the characteristics of ZrB2-based composites reinforced with SiC whiskers. Diamond Relat. Mater. 105:107786. doi: 10.1016/j.diamond.2020.107786

Asrami, P. N., Mozaffari, S. A., Tehrani, M. S., and Azar, P. A. (2018). A novel impedimetric glucose biosensor based on immobilized glucose oxidase on a CuO-Chitosan nanobiocomposite modified FTO electrode. Int. J. Biol. Macromol. 118, 649-660. doi: 10.1016/j.ijbiomac.2018.05.228

Asrami, P. N., Tehrani, M. S., Azar, P. A., and Mozaffari, S. A. (2017). Impedimetric glucose biosensor based on nanostructure nickel oxide transducer fabricated by reactive RF magnetron sputtering system. J. Electroanal. Chem. 801, 258-266. doi: 10.1016/j.jelechem.2017.07.052 confirming the high capacity of the fabricated sensor for the real sample analysis of anticancer drugs.

\section{DATA AVAILABILITY STATEMENT}

All datasets presented in this study are included in the article/Supplementary Material.

\section{AUTHOR CONTRIBUTIONS}

MA: experimental part as a Ph.D. student. PA and SM: introduce thesis and work as supervisor. HK-M and A-MT: write the paper and advisor of work. All authors contributed to the article and approved the submitted version.

\section{SUPPLEMENTARY MATERIAL}

The Supplementary Material for this article can be found online at: https://www.frontiersin.org/articles/10.3389/fchem. 2020.00677/full\#supplementary-material

Atta, N. F., Galal, A., and Hassan, S. H. (2019). Ultrasensitive determination of nalbuphine and tramadol narcotic analgesic drugs for postoperative pain relief using nano-cobalt oxide/ionic liquid crystal/carbon nanotubesbased electrochemical sensor. J. Electroanal. Chem. 839, 48-58. doi: 10.1016/j.jelechem.2019.03.002

Baghayeri, M., Ghanei-Motlagh, M., Tayebee, R., Fayazi, M., and Narenji, F. (2020). Application of graphene/zinc-based metal-organic framework nanocomposite for electrochemical sensing of As (III) in water resources. Anal. Chim. Acta 1099, 60-67. doi: 10.1016/j.aca.2019.11.045

Baghayeri, M., Namadchian, M., Karimi-Maleh, H., and Beitollahi, H. (2013). Determination of nifedipine using nanostructured electrochemical sensor based on simple synthesis of Ag nanoparticles at the surface of glassy carbon electrode: application to the analysis of some real samples. J. Electroanal. Chem. 697, 53-59. doi: 10.1016/j.jelechem.2013.03.011

Baghayeri, M., Nodehi, M., Veisi, H., Tehrani, M. B., Maleki, B., and Mehmandost, M. (2019). The role of pramipexole functionalized MWCNTs to the fabrication of Pd nanoparticles modified GCE for electrochemical detection of dopamine. DARU J. Pharma. Sci. 27, 593-603. doi: 10.1007/s40199-019-00287-y

Bernstein, L., and Ross, R. K. (1993). Endogenous hormones and breast cancer risk. Epidemiol. Rev. 15, 48-65. doi: 10.1093/oxfordjournals.epirev.a036116

Beytur, M., Kardaş, F., Akyildirim, O., Özkan, A., Bankoglu, B., Yüksek, H., et al. (2018). A highly selective and sensitive voltammetric sensor with molecularly imprinted polymer based silver@ gold nanoparticles/ionic liquid modified glassy carbon electrode for determination of ceftizoxime. J. Mol. Liquids 251, 212-217. doi: 10.1016/j.molliq.2017.12.060 
Dehdashti, A., and Babaei, A. (2020). Highly sensitive electrochemical sensor based on Pt doped $\mathrm{NiO}$ nanoparticles/MWCNTs nanocomposite modified electrode for simultaneous sensing of piroxicam and amlodipine. Electroanalysis 32, 1017-1024. doi: 10.1002/elan.201900580

Delaney, G., Jacob, S., Featherstone, C., and Barton, M. (2005). The role of radiotherapy in cancer treatment: estimating optimal utilization from a review of evidence-based clinical guidelines. Cancer Interdiscipl. Int. J. Am. Cancer Soc. 104, 1129-1137. doi: 10.1002/cncr.21324

Fattahi, M., Asl, M. S., Delbari, S. A., Namini, A. S., Ahmadi, Z., and Mohammadi, M. (2020). Role of nano-WC addition on microstructural, mechanical and thermal characteristics of TiC-SiCw composites. Int. J. Refrac. Metals Hard Mater. 90:105248. doi: 10.1016/j.ijrmhm.2020.105248

Fu, L., Wang, A., Xie, K., Zhu, J., Chen, F., Wang, H., et al. (2020). Electrochemical detection of silver ions by using sulfur quantum dots modified gold electrode. Sens. Actuat. B Chem. 304:127390. doi: 10.1016/j.snb.2019.127390

Fu, L., Wu, M., Zheng, Y., Zhang, P., Ye, C., Zhang, H., et al. (2019a). Lycoris species identification and infrageneric relationship investigation via graphene enhanced electrochemical fingerprinting of pollen. Sens. Actuat. B Chem. 298, 126836. doi: 10.1016/j.snb.2019.126836

Fu, L., Xie, K., Wang, A., Lyu, F., Ge, J., Zhang, L., et al. (2019c). High selective detection of mercury (II) ions by thioether side groups on metal-organic frameworks. Anal. Chim. Acta 1081, 51-58. doi: 10.1016/j.aca.2019.06.055

Fu, L., Zheng, Y., Zhang, P., Zhang, H., Wu, M., Zhang, H., et al. (2019b). An electrochemical method for plant species determination and classification based on fingerprinting petal tissue. Bioelectrochemistry 129, 199-205. doi: 10.1016/j.bioelechem.2019.06.001

Fu, L., Zheng, Y., Zhang, P., Zhang, H., Zhuang, W., Zhang, H., et al. (2018). Enhanced electrochemical voltammetric fingerprints for plant taxonomic sensing. Biosens. Bioelectron. 120, 102-107. doi: 10.1016/j.bios.2018.08.052

Gavenda, A., Ševčík, J., Psotová, J., Bednár, P., Barták, P., Adamovský, P., et al. (2001). Determination of anthracycline antibiotics doxorubicin and daunorubicin by capillary electrophoresis with UV absorption detection. Electrophoresis 22, 2782-2785. doi: 10.1002/1522-2683(200108)22:13<2782::AID-ELPS2782>3.0.CO;2-I

Ghanei-Motlagh, M., and Baghayeri, M. (2020). Determination of trace Tl (I) by differential pulse anodic stripping voltammetry using a novel modified carbon paste electrode. J. Electrochem. Soc. 167:066508. doi: 10.1149/1945-7111/ab823c

Guo, J., and Lu, W.-L. (2010). Effects of stealth liposomal daunorubicin plus tamoxifen on the breast cancer and cancer stem cells. J. Pharma. Pharma. Sci. 13, 136-151. doi: 10.18433/J3P88Z

Hu, Q., Zhang, L., Zhou, T., and Fang, Y. (2000). Determination of daunorubicin in human urine by capillary zone electrophoresis with amperometric detection. Anal. Chim. Acta 416, 15-19. doi: 10.1016/S0003-2670(00) 00856-4

Hulhoven, R., and Desager, J. (1977). HPLC determination of daunorubicin and daunorubicinol in human plasma. Biomedicine 27, 102-104.

Jiang, C.-Q., Gao, M.-X., and Meng, X.-Z. (2003). Study of the interaction between daunorubicin and human serum albumin, and the determination of daunorubicin in blood serum samples. Spectrochim. Acta A Mol. Biomol. Spectrosc. 59, 1605-1610. doi: 10.1016/S1386-1425(02)00362-1

Karimi-Maleh, H., and Arotiba, O. A. (2020). Simultaneous determination of cholesterol, ascorbic acid and uric acid as three essential biological compounds at a carbon paste electrode modified with copper oxide decorated reduced graphene oxide nanocomposite and ionic liquid. J. Colloid Interface Sci. 560, 208-212. doi: 10.1016/j.jcis.2019.10.007

Karimi-Maleh, H., Cellat, K., Arikan, K., Savk, A., Karimi, F., and Sen, F. (2020b). Palladium-Nickel nanoparticles decorated on Functionalized-MWCNT for high precision non-enzymatic glucose sensing. Mater. Chem. Phys. 250:123042. doi: 10.1016/j.matchemphys.2020.123042

Karimi-Maleh, H., Fakude, C. T., Mabuba, N., Peleyeju, G. M., and Arotiba, O. A. (2019a). The determination of 2-phenylphenol in the presence of 4-chlorophenol using nano- $\mathrm{Fe}_{3} \mathrm{O}_{4} /$ ionic liquid paste electrode as an electrochemical sensor. J. Colloid Interface Sci. 554, 603-610. doi: 10.1016/j.jcis.2019.07.047

Karimi-Maleh, H., Ganjali, M. R., Norouzi, P., and Bananezhad, A. (2017). Amplified nanostructure electrochemical sensor for simultaneous determination of captopril, acetaminophen, tyrosine and hydrochlorothiazide. Mater. Sci. Eng. C 73, 472-477. doi: 10.1016/j.msec.2016.12.094
Karimi-Maleh, H., Karimi, F., Alizadeh, M., and Sanati, A. L. (2020a). Electrochemical sensors, a bright future in the fabrication of portable kits in analytical systems. Chem. Rec. 20:123042. doi: 10.1002/tcr.201900092

Karimi-Maleh, H., Karimi, F., Malekmohammadi, S., Zakariae, N., Esmaeili, R., Rostamnia, S., et al. (2020d). An amplified voltammetric sensor based on platinum nanoparticle/polyoxometalate/two-dimensional hexagonal boron nitride nanosheets composite and ionic liquid for determination of N-hydroxysuccinimide in water samples. J. Mol. Liquids 310:113185. doi: 10.1016/j.molliq.2020.113185

Karimi-Maleh, H., Shafieizadeh, M., Taher, M. A., Opoku, F., Kiarii, E. M., Govender, P. P., et al. (2020c). The role of magnetite/graphene oxide nanocomposite as a high-efficiency adsorbent for removal of phenazopyridine residues from water samples, an experimental/theoretical investigation. J. Mol. Liquids 298:112040. doi: 10.1016/j.molliq.2019.112040

Karimi-Maleh, H., Sheikhshoaie, M., Sheikhshoaie, I., Ranjbar, M., Alizadeh, J., Maxakato, N. W., et al. (2019b). A novel electrochemical epinine sensor using amplified $\mathrm{CuO}$ nanoparticles and an-hexyl-3methylimidazolium hexafluorophosphate electrode. New J. Chem. 43, 2362-2367. doi: 10.1039/C8NJ05581E

Keyvanfard, M., Ahmadi, M., Karimi, F., and Alizad, K. (2014). Voltammetric determination of cysteamine at multiwalled carbon nanotubes paste electrode in the presence of isoproterenol as a mediator. Chin. Chem. Lett. 25, 1244-1246. doi: $10.1016 /$ j.cclet.2014.05.018

Khodadadi, A., Faghih-Mirzaei, E., Karimi-Maleh, H., Abbaspourrad, A., Agarwal, S., and Gupta, V. K. (2019). A new epirubicin biosensor based on amplifying DNA interactions with polypyrrole and nitrogen-doped reduced graphene: experimental and docking theoretical investigations. Sens. Actuat. B Chem. 284, 568-574. doi: 10.1016/j.snb.2018.12.164

Li, M., Yu, H., Wang, T., Chang, N., Zhang, J., Du, D., et al. (2014). Tamoxifen embedded in lipid bilayer improves the oncotarget of liposomal daunorubicin in vivo. J. Mater. Chem. B 2, 1619-1625. doi: 10.1039/c3tb21423k

Li, Y., Ji, Y., Ren, B., Jia, L., Ma, G., and Liu, X. (2019). Carboxyl-functionalized mesoporous molecular sieve/colloidal gold modified nano-carbon ionic liquid paste electrode for electrochemical determination of serotonin. Mater. Res. Bull. 109, 240-245. doi: 10.1016/j.materresbull.2018.10.002

Malekmohammadi, S., Hadadzadeh, H., and Amirghofran, Z. (2018b). Preparation of folic acid-conjugated dendritic mesoporous silica nanoparticles for $\mathrm{pH}$-controlled release and targeted delivery of a cyclometallated gold (III) complex as an antitumor agent. J. Mol. Liquids 265, 797-806. doi: 10.1016/j.molliq.2018.07.024

Malekmohammadi, S., Hadadzadeh, H., Farrokhpour, H., and Amirghofran, Z. (2018a). Immobilization of gold nanoparticles on folate-conjugated dendritic mesoporous silica-coated reduced graphene oxide nanosheets: a new nanoplatform for curcumin $\mathrm{pH}$-controlled and targeted delivery. Soft Matter 14, 2400-2410. doi: 10.1039/C7SM02248D

Mohanraj, J., Durgalakshmi, D., Rakkesh, R. A., Balakumar, S., Rajendran, S., and Karimi-Maleh, H. (2020). Facile synthesis of paper based graphene electrodes for point of care devices: A double stranded DNA (dsDNA) biosensor. J. Colloid Interface Sci. 566, 463-472. doi: 10.1016/j.jcis.2020.01.089

Moseley, A. L., Carati, C. J., and Piller, N. B. (2007). A systematic review of common conservative therapies for arm lymphoedema secondary to breast cancer treatment. Ann. Oncol. 18, 639-646. doi: 10.1093/annonc/mdl182

Mozaffari, S. A., Rahmanian, R., Abedi, M., and Amoli, H. S. (2014). Urea impedimetric biosensor based on reactive RF magnetron sputtered zinc oxide nanoporous transducer. Electrochim. Acta 146, 538-547. doi: 10.1016/j.electacta.2014.08.105

Mozaffari, S. A., Ranjbar, M., Kouhestanian, E., Amoli, H. S., and Armanmehr, M. (2015). An investigation on the effect of electrodeposited nanostructured $\mathrm{ZnO}$ on the electron transfer process efficiency of $\mathrm{TiO}_{2}$ based DSSC. Mater. Sci. Semicond. Process. 40, 285-292. doi: 10.1016/j.mssp.2015.06.081

Nayebi, B., Asl, M. S., Kakroudi, M. G., and Shokouhimehr, M. (2016). Temperature dependence of microstructure evolution during hot pressing of $\mathrm{ZrB}_{2}-30$ vol.\% SiC composites. Int. J. Refrac. Metals Hard Mater. 54, 7-13. doi: 10.1016/j.ijrmhm.2015.06.017

Nguyen, T. P., Asl, M. S., Delbari, S. A., Namini, A. S., Van Le, Q., Shokouhimehr, M., et al. (2020). Electron microscopy investigation of spark plasma sintered $\mathrm{ZrO}_{2}$ added $\mathrm{ZrB}_{2}$-SiC composite. Ceramics Int. 46, 19646-19649. doi: 10.1016/j.ceramint.2020.04.292 
Nodehi, M., Baghayeri, M., Ansari, R., and Veisi, H. (2020). Electrochemical quantification of $17 \alpha$-ethinylestradiol in biological samples using a $\mathrm{Au} / \mathrm{Fe}_{3} \mathrm{O}_{4} @$ TA/MWNT/GCE sensor. Mater. Chem. Phys. 244:122687. doi: 10.1016/j.matchemphys.2020.122687

Orooji, Y., Alizadeh, A. A., Ghasali, E., Derakhshandeh, M. R., Alizadeh, M., Asl, M. S., et al. (2019b). Co-reinforcing of mullite-TiN-CNT composites with $\mathrm{ZrB}_{2}$ and $\mathrm{TiB}_{2}$ compounds. Ceramics Int. 45, 20844-20854. doi: 10.1016/j.ceramint.2019.07.072

Orooji, Y., Derakhshandeh, M. R., Ghasali, E., Alizadeh, M., Asl, M. S., and Ebadzadeh, T. (2019c). Effects of $\mathrm{ZrB}_{2}$ reinforcement on microstructure and mechanical properties of a spark plasma sintered mullite-CNT composite. Ceramics Int. 45, 16015-16021. doi: 10.1016/j.ceramint.2019.05.113

Orooji, Y., Ghasali, E., Moradi, M., Derakhshandeh, M. R., Alizadeh, M., Asl, M. S., et al. (2019a). Preparation of mullite-TiB $2-C N T s$ hybrid composite through spark plasma sintering. Ceramics Int. 45, 16288-16296. doi: 10.1016/j.ceramint.2019.05.154

Parvizi, S., Ahmadi, Z., Zamharir, M. J., and Asl, M. S. (2018). Synergistic effects of graphite nano-flakes and submicron $\mathrm{SiC}$ particles on the characteristics of spark plasma sintered $\mathrm{ZrB}_{2}$ nanocomposites. Int. J. Refrac. Metals Hard Mater. 75, 10-17. doi: 10.1016/j.ijrmhm.2018.03.017

Radwan, A., Khalid, M., Amer, H., and Alotaibi, M. (2019). Anticancer and molecular docking studies of some new pyrazole-1carbothioamide nucleosides. Biointerface Res. Appl. Chem. 9, 4642-4648. doi: 10.33263/BRIAC96.642648

Rahmanian, R., and Mozaffari, S. A. (2015). Electrochemical fabrication of ZnOpolyvinyl alcohol nanostructured hybrid film for application to urea biosensor. Sens. Actuat. B Chem. 207, 772-781. doi: 10.1016/j.snb.2014.10.129

Rahmanian, R., Mozaffari, S. A., and Abedi, M. (2015). Disposable urea biosensor based on nanoporous $\mathrm{ZnO}$ film fabricated from omissible polymeric substrate. Mater. Sci. Eng. C 57, 387-396. doi: 10.1016/j.msec.2015.08.004

Raut, L. S. (2015). Novel formulation of cytarabine and daunorubicin: a new hope in AML treatment. South Asian J. Cancer 4:38. doi: 10.4103/2278-330X.149950

Rayati, S., and Malekmohammadi, S. (2016). Catalytic activity of multi-wall carbon nanotube supported manganese (III) porphyrin: an efficient, selective and reusable catalyst for oxidation of alkenes and alkanes with ureahydrogen peroxide. J. Exp. Nanosci. 11, 872-883. doi: 10.1080/17458080.2016. 1179802

Reiffers, J., Huguet, F., Stoppa, A., Molina, L., Marit, G., Attal, M., et al. (1996). A prospective randomized trial of idarubicin vs daunorubicin in combination chemotherapy for acute myelogenous leukemia of the age group 55 to 75 . Leukemia 10, 389-395.

Sakkaki, M., Moghanlou, F. S., Vajdi, M., Asl, M. S., Mohammadi, M., and Shokouhimehr, M. (2020). Numerical simulation of heat transfer during spark plasma sintering of zirconium diboride. Ceramics Int. 46, 4998-5007. doi: 10.1016/j.ceramint.2019.10.240

Shamsadin-Azad, Z., Taher, M. A., Cheraghi, S., and Karimi-Maleh, H. (2019). A nanostructure voltammetric platform amplified with ionic liquid for determination of tert-butylhydroxyanisole in the presence kojic acid. J. Food Meas. Charac. 13, 1781-1787. doi: 10.1007/s11694-01900096-6

Shao, M., Sun, S., Li, M., Li, B., Yu, H., Shen, Z., et al. (2012). The liposomal daunorubicin plus tamoxifen: improving the stability, uptake, and biodistribution of carriers. J. Lipos. Res. 22, 168-176. doi: 10.3109/08982104.2012.668552

Shien, T., Iwata, H., Aogi, K., Fukutomi, T., Inoue, K., Kinoshita, T., et al. (2014). Tamoxifen versus tamoxifen plus doxorubicin and cyclophosphamide as adjuvant therapy for node-positive postmenopausal breast cancer: results of a Japan Clinical Oncology Group Study (JCOG9401). Int. J. Clin. Oncol. 19, 982-988. doi: 10.1007/s10147-013-0657-z

Skovsgaard, T. (1978). Mechanisms of resistance to daunorubicin in Ehrlich ascites tumor cells. Cancer Res. 38, 1785-1791.

Slater, L. M., Murray, S. L., Wetzel, M. W., Wisdom, R. M., and Duvall, E. M. (1982). Verapamil restoration of daunorubicin responsiveness in daunorubicin-resistant Ehrlich ascites carcinoma. J. Clin. Invest. 70, 1131-1134. doi: 10.1172/JCI110702

Tahernejad-Javazmi, F., Shabani-Nooshabadi, M., and Karimi-Maleh, H. (2019). 3D reduced graphene oxide/FeNi3-ionic liquid nanocomposite modified sensor; an electrical synergic effect for development of tertbutylhydroquinone and folic acid sensor. Compos. B Eng. 172, 666-670. doi: 10.1016/j.compositesb.2019.05.065

Trichopoulos, D., MacMahon, B., and Cole, P. (1972). Menopause and breast cancer risk. J. Natl. Cancer Inst. 48, 605-613.

Wang, J., Lin, M. S., and Villa, V. (1987). Adsorptive stripping voltammetric determination of low levels of daunorubicin. Analyst 112, 1303-1307. doi: 10.1039/an9871201303

Xu, C., Zhang, S., Zang, H., Yuan, B., Fan, R., Zhang, N., et al. (2018). A simple and facile electrochemical sensor for sensitive detection of histidine based on three-dimensional porous Ni foam. Int. J. Electrochem. Sci 13, 9794-9802. doi: $10.20964 / 2018.10 .60$

Yang, P., Zeng, F., and Pan, F. (2010). Exchange bias and training effect in $\mathrm{Ni} /$ Ag-doped $\mathrm{NiO}$ bilayers. J. Magn. Magn. Mater. 322, 542-547. doi: 10.1016/j.jmmm.2009.10.012

Yuan, B., Sun, P., Zhao, L., Zhang, D., Zhang, Y., Qi, C., et al. (2020). Pd nanoparticles supported on 1,10-phenanthroline-5,6-dione modified graphene oxide as superior bifunctional electrocatalyst for highly sensitive sensing. J. Electroanal. Chem. 861:113945. doi: 10.1016/j.jelechem.2020.113945

Yuan, B., Wang, H., Cai, J., Peng, Y., Niu, Y., Chen, H., et al. (2019). A novel oxidation-reduction method for highly selective detection of cysteine over reduced glutathione based on synergistic effect of fully fluorinated cobalt phthalocyanine and ordered mesoporous carbon. Sens. Actuat. B Chem. 288, 180-187. doi: 10.1016/j.snb.2019.02.114

Yuan, B., Xu, C., Deng, D., Xing, Y., Liu, L., Pang, H., et al. (2013). Graphene oxide/nickel oxide modified glassy carbon electrode for supercapacitor and nonenzymatic glucose sensor. Electrochim. Acta 88, 708-712. doi: 10.1016/j.electacta.2012.10.102

Yuan, B., Xu, C., Zhang, R., Lv, D., Li, S., Zhang, D., et al. (2017). Glassy carbon electrode modified with 7,7,8,8-tetracyanoquinodimethane and graphene oxide triggered a synergistic effect: low-potential amperometric detection of reduced glutathione. Biosens. Bioelectron. 96, 1-7. doi: 10.1016/j.bios.2017.04.026

Conflict of Interest: The authors declare that the research was conducted in the absence of any commercial or financial relationships that could be construed as a potential conflict of interest.

The reviewer FK declared a past co-authorship with one of the authors HK-M to the handling editor.

Copyright (C) 2020 Alizadeh, Azar, Mozaffari, Karimi-Maleh and Tamaddon. This is an open-access article distributed under the terms of the Creative Commons Attribution License (CC BY). The use, distribution or reproduction in other forums is permitted, provided the original author(s) and the copyright owner(s) are credited and that the original publication in this journal is cited, in accordance with accepted academic practice. No use, distribution or reproduction is permitted which does not comply with these terms. 